\title{
Virtual Reference Training: The Second Generation
}

\author{
Lynn Westbrook
}

\begin{abstract}
First-generation digital reference training centered on technology, policies, procedures, and basic online communication tactics. Recent research and theoretical developments in adult education, digital communication, cognitive psychology, and human-computer interaction can move digital reference training into its second generation. Synthesizing current interdisciplinary developments, this paper presents four overarching guidelines and essential training principles for each stage of the reference interview.
\end{abstract}

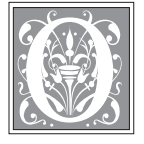

ver the past quarter century, reference staff have been taught to use interview techniques rooted in adult learning, cognitive psychology, and interpersonal communication theory. At its best, the first generation of digital reference training builds on this rich foundation by centering on the patron's contextualized information need rather than the potentials of any particular technology. ${ }^{1}$ Of necessity, however, these first efforts often focused on the functional essentials of software, procedures, and communication tactics. ${ }^{2}$ Now that this service is well established, ${ }^{3}$ it is time to incorporate recent theoretical advancements regarding digital interactions from our sister disciplines. This paper's synthesis of recent theoretical and research work in psychology, education, communication, and human-computer interaction (HCI) applies recent critical works to specific stages of the digital reference interaction. Both enhancing and updating the multidisciplinary foundations of refer- ence work, this paper provides a two-tier framework for second-generation digital reference training: (1) four overarching guidelines and (2) interaction strategies for each stage of the interview.

\section{Overarching Guidelines: Quality, Engagement, Comprehension, Instruction}

Assuming that a well-run service has met the basic staff training goals mentioned above, the most experienced and bestprepared staff are still functioning in a multilayered environment where naive patrons use high-end equipment while industry standards are still in flux. Every stage of the reference interview, therefore, is a tightrope walk between skyscrapers and the following guidelines can serve as a balancing pole.

\section{Quality}

The hyper-evolution of digital communication leaves little opportunity for development of a shared, socially rooted understanding of a "high-quality"

Lynn Westbrook is an Assistant Professor in the School of Information at the University of Texas at Austin; e-mail:lynnwest@ischool.utexas.edu. 
interaction. The immediate context of a digital interaction, even though fluid and multidimensional, may well take precedence over individual demographic factors in social identity development such as race or sex. ${ }^{4}$ In terms of quality, therefore, great care must be taken to focus on the patron's immediate situation without undue attention paid to, for example, the easy use of chat room shorthand common to middle-class undergraduates. Such ease may not indicate a low-anxiety level, comfort with information technology, or a casual attitude toward the problem at hand.

"Scaffolding" 5 in cyberspace provides academic librarians with their most effective quality support, particularly when dealing with patrons who are operating on the basis of inaccurate information. The business model focus on demanding the least possible effort from consumers, when applied too enthusiastically in universities, risks carefully maintaining a user's inaccurate perspective. By denigrating professional judgment in favor of user convenience, librarians abnegate their professional responsibility; scaffolding helps bridge patrons from one stage to the next in their understanding of an information concern. For example, patrons who firmly believe that the Internet holds the best answers to their questions might be well satisfied with the quality of librarians who accept their belief as a given, working from there to find answers. However, some of those patrons might be better served in the long run by librarians who are willing to use scaffolding to help them build a more accurate mental model of information resources so that the patron can make use of, for example, scholarly databases. ${ }^{6}$ The interchange of chat, which has the ability to "push" appropriate pages when the patron is ready, facilitates scaffolding.

\section{Engagement}

Patrons must believe that additional reference and/or instructional support is readily available. Initial work on availability has already incorporated such valuable tools as "ask-a-librarian" buttons embedded throughout a university's Web site, invitations to ask additional questions as a standard part of each interview, and the use of neutral questions. The few cues available to indicate the genuine strength of that electronic offer must be reinforced with repetition, prompt responses, and warmly personalized service.

Building on these productive means of engaging users, librarians who work to deepen their understanding of the user's perspective, risks, and information-need focus issues must match that user-centered effort with a self-reflective ethos. Demanding of themselves an awareness of their own mental models, behavioral norms, and communication expectations, self-reflective practitioners consider both affective and cognitive factors in the interview process. Although "the affect/cognition relationship is fundamentally an interactive one," peeling the two apart facilitates recognition of their impact. ${ }^{7}$

Agitation and library anxiety are emotional factors that can seriously impact a patron's level of engagement during the reference interview, necessitating deft use of digital nuance indicators. These are sparse indeed but do exist in forms such as the incomplete expressions of ideas, rapid-fire demands for attention, and a refusal to respond clearly to closed questions. Affective concerns cause people to revise conceptual categories, a change that alters perceptions of similarities and differences between items. In addition to altering memories, therefore, emotions actually change cognitive categories and the use made of those categories. ${ }^{8}$ Reference interviews that begin by echoing negative emotional experiences can lead to categorizing the entire experience as negative before the librarian is even fully aware of the information need. Patrons may make these judgments on the basis of online forms or a chat room opening because "evaluative, affective responses can often be produced 
in a fast, automatic, and highly adaptive manner even in the absence of inferential cognitive deliberations." 9

Agitation can be a determining factor in interview success or failure. Calm people move through the information-seeking process much more readily than do tense, anxious, agitated people. Students working against a tight deadline might, for example, feel driven to attempt an online reference interview for the first time but then find themselves too impatient to explain the intricacies of their information gaps. Even "subtle changes in our affective states can have a pronounced impact on what and how we think. Affective states can influence encoding, retrieval, and judgment processes, as well as strategies of information processing." ${ }^{10}$ As might be expected, more complex and involved research generates stronger affective responses. The "infusion of affect into judgment and decisions is most likely in conditions requiring constructive, substantive processing." 11

Library anxiety entails tension about, and even fear of, libraries centering on a sense of skill inadequacy, a need to hide this shameful inadequacy, and the conviction that asking for assistance reveals the inadequacy. Sometimes related to low self-efficacy beliefs regarding computer use or Internet search skills, library anxiety continues to inhibit the full expression of needs. Nevertheless, librarians who are good facilitators bring those who want the convenience of online reference up to a comfort level that supports the interaction. $^{12}$

The emotions and motivations of the affective state have a profound effect on engagement during the entire information-seeking process; they are not simply a nuisance to be erased before dealing with the "real" issues. They are "an important and independent source of functional information and input into realistic judgmental and informationprocessing tasks."13 Fortunately, recent social psychology research indicates that the purely verbal mediums of e-mail and chat communication are actually quite effective in the arena of building positive affective connections. In addition to clear statements of positive affection, "being indirect in disagreements and offering praise while proposing a different idea" can be used effectively in online communication "to preserve the face of, and engender liking from, a conversational partner." ${ }^{14}$ Because emotions may "guide attention to certain kinds of information"15 in decision-making and problem-solving situations, responses should incorporate acknowledgment of emotional content on, at least, a tacit level.

\section{Comprehension}

In addition to affective factors, the following cognitive factors may come into play before initial contact is made: experiential patterns, domain knowledge, service expectations, and mental models. Librarians rarely see more than indicators of these factors and must work hard to glean enough detail to respond supportively.

Experiential patterns of information work, as librarians have long acknowledged, indicate that libraries, much less reference interviews, are rarely the first choice for people who need information. The convenience and comfort level of preferred information sources form part of the essential background work for most people prior to reaching the library. Although in-person service, particularly when it is proactive, might lead to an interview in the midst of the patron's internal self-consultation at the very moment when a need moves from the conscious to the formalized state, ${ }^{16}$ online interviews are entirely at the instigation of the patron. Patrons utilizing digital services are, therefore, more likely to have already been through their own internal and social resources. The attendant potential for misconceptions, wellexplored dead ends, and compromised information-need statements must be anticipated, although not assumed. HCI research indicates that users need at least a signpost indicating they are on the right 
track within three clicks; also vetting sites for confidentiality protection and quality is not a standard behavior. ${ }^{17}$ Obviously, what precedes an interview contact is both dubious and widely variable.

Browsing, for example, requires a belief that something relevant to an information need is available, a belief based on experience with an information environment. The ability to adapt both purpose and browsing tactics is inherent in self-regulated browsing. ${ }^{18}$ In addition to browsing, scanning and sheer serendipity ${ }^{19}$ develop relevance criteria, reshape expressions of the information need, and influence expectations.

Domain knowledge can contribute substantially to the conceptual understanding of the need, the specificity and nature of search terms, and the relevance criteria employed. ${ }^{20}$ However, challenging information processing occurs when "people need to actually select, learn, and interpret novel information and relate this information to their preexisting knowledge structures in order to construct a response." This kind of domain knowledge processing is more likely to occur "when the task is complex, novel, or atypical; there is no motivational goal to dominate processing; there is adequate cognitive capacity; and/or the situation calls for constructive, elaborate processing." 21 These are the points at which the just-in-time nature of digital reference can make a significant difference in the patron's comprehension of both the information needed and, at times, the complexities of the information problem itself.

Service expectations vary not only among patrons, but also among librarians, particularly in newly developing service arenas. In a digital forum, pushing a preformatted pathfinder on the topic area can be as inadequate as pointing to a shelf of books. Similarly, the patron's informal chat room shorthand may clash with the librarian's professional reference tone. ${ }^{22}$ First-generation digital reference training emphasized that the consistent application of policies and procedures helped solve such service expectation inconsistencies or lapses, but psychology and HCI research lead us to believe that additional measures might be fruitful for this second generation of virtual reference training.

Individuals use the Internet for a wide range of personal goals, including selfexpression, affiliation, and competition. ${ }^{23}$ Those goals impact the expectations people hold of the communication style and content they will encounter. Therefore, training must include tactful means of steering socially rooted interactions back into professional channels when, for example, the informality of an effective chat session leads a naïve user to expect an "affiliation"-centered exchange or when a statement of need becomes more self-expression than information-need expression. This is particularly important for those who demonstrate evidence of the "online disinhibition effect" 24 via inappropriate self-disclosure or emotional interaction.

One commonly held expectation of e-mail communication is that messages are read quickly and, consequently, any delay in response is an indication of disinterest or even disrespect. ${ }^{25}$ Form e-mails in response may mitigate the effects of that expectation, but some personalized, meaningful explanation of any delay, particularly an explanation relating to the effort to search for a high-quality answer, is essential. In chat forums, however, a reasonable delay is actually helpful. A delay that is too brief to be seen as a result of the user's last message is deemed uncomfortable. ${ }^{26}$ This reinforces the longstanding practice of making sure that patrons understand something of the effort being put forth on their behalf as part of giving them a satisfactory response.

The mental model that each patron holds regarding the world of information is a cognitive factor that impacts behaviors, decision criteria, and relevance criteria. From the cognitive psychology perspective, "a mental model of a dynamic system is a relatively enduring and accessible, but 
limited, internal conceptual representation of an external system whose structure maintains the perceived structure of that system." ${ }^{27}$ People often hold multiple models of complex systems, some of which are abstract and others of which relate closely to specific contexts. ${ }^{28}$ People frame their questions according to their mental models, and those who hold half-formed, ill-informed, or outdated mental models of how various information elements are supposed to work will need special help. This is particularly important in digital reference because the media frequently present the Internet as a well-ordered cornucopia of digested data. Correcting and developing more realistic mental models help users "make significantly fewer errors and find significantly more items. ${ }^{29}$ Individuals with poor spatial visualization abilities are more likely to have difficulties in using hierarchical databases, ${ }^{30}$ possibly because of inaccurate mental models. Support for visualization efforts can be productive in both correcting errors and speeding the search process.

\section{Instruction}

Throughout the interview, librarians need to stay within the "zone of proximal development" by focusing on activities that are just beyond what patrons can do on their own, but that are well within reach of what they can do if they have support. ${ }^{31}$ Also known as constructivism, this educational theory builds on mental model research to establish points at which librarians can connect those models to what an individual already knows, which develops and/or corrects the mental models. ${ }^{32}$

The social cognitive theories on the relationship between motivation and selfregulation have marked implications for instructional interviews. Although selfregulated learning is ideal, many patrons (particularly undergraduates) are still developing the ability to self-observe, selfjudge, and self-react. Motivation, even in the face of failure, generally increases when an individual's self-observations, judgments, and reactions are favorable..$^{33}$ Therefore, reinforcing the strengths in an information-seeking effort may be all the more important when some instruction is needed. In fact, the effectiveness of that instruction may increase in relationship to the patron's ability to self-regulate learning, assuming that no issues of negative self-efficacy beliefs regarding Internet use interfere. ${ }^{34}$

\section{Interaction Strategies for Each Stage of the Interview}

Although information seeking is often a

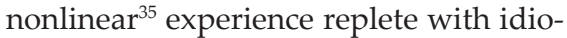
syncratic choices, the reference interview process is more likely to form a cohesive narrative with a beginning, middle, and end. The digital format actually reinforces that staged process by putting control of the communication in the user's hands during each of the seven common stages of the reference interview: opening, establishing the information need and user's affective state, confirming and clarifying the question, conducting the search, answering the question, making sense of the answer, and closing the interview. Imperceptible to the patron, these stages require meta-cognitive analysis from the librarian.

\section{Opening the Interview}

As first-generation service design has so clearly established, the standard rule that librarians must be proactive requires design of a cyberspace in which patrons are invited with imagination, vigor, and variety to make contact. Truly customized, one-stop-shopping, bidirectional portals ${ }^{36}$ can stand as the embodiment of this invitation. However, even the bestdesigned digital library can contribute to the problem that leads an individual to ask for assistance. One study indicates that about 38 percent of computer time is spent in frustrating experiences..$^{37}$ That affective momentum is more likely to be a factor for some patrons, such as the women who report lower perceptions 
of computer self-efficacy than do some males. $^{38}$

Certainly most patrons do not even recognize the existence of the "reference interview" as a particular communication structure. This fundamental difference in the mental model both parties hold of the activity can trigger dissonance in the pacing, tenor, tone, and general quality of the interaction. Librarians may expect, for example, online patrons to prize speed quite highly when, in fact, they might be more patient than in-person patrons simply because they are using a communication mode they find convenient and socially comfortable. ${ }^{39}$ In particularly complex information tasks, the flow of searching may be stymied and the reference interview becomes a means to break the bottleneck, or detailed records of multiple information searches ${ }^{40}$ may be proliferating in the background as multitasking continues during the contact. Research on working memory, however, indicates that the "extent and type of errors in remembering" are adversely affected by messages that interrupt information assimilation and exchange. ${ }^{41}$ The opening exchanges in the digital reference interview bear a particular weight when all these factors are considered.

\section{Establishing the Information Need and User's Affective State}

When contact is established, communication guidelines come to the fore. As first-generation training notes, librarians must make full use of typical conventions of online communication (e.g., short sentences, sentence fragments, abbreviations, dropped punctuation, and formatting for emphasis) to establish rapport and start to build trust. ${ }^{42}$

Carefully noting a patron's use of these online communication conventions provides a context for replying. Balance must be maintained between two, sometimes competing, goals: increasing the user's affective comfort level with the interaction and establishing realistic expectations for the reference transaction. For example, echoing the patron's use of abbreviations may help to establish rapport, but care must be taken that it does not also inadvertently support the expectation that resolving a complex need is far more simple than it really is.

One final aspect of this stage grows from the contrast between traditional educational methods (i.e., inductive and deductive reasoning) and the oftenneglected contributions of abductive reasoning. Given the ever-growing complexity of information decisions made on a daily basis by intellectually and socially active individuals, the time and data required for traditionally supported logic patterns may simply not exist..$^{43}$ As patrons explain their information needs, traces of abductive reasoning may appear in their use of intuitive theories about their best course of action without reference to hard facts or evidentiary proofs. The choice to accept, clarify, augment, or correct a hypothesis based on abductive reasoning is a delicate one and may best be left for later stages of the interview process.

\section{Confirming and Clarifying the Question}

Actively listening to the question and then restating it demonstrates an interest in the problem as well as a commitment to solving it. Sometimes simply stating the question triggers a clarification that is part of the search process for the patron, narrowing or redefining the need in terms of domain knowledge, service expectations, or relevance criteria. Digital forums that permit the use of criteria menus can speed the process for patrons while leaving sufficient choices to genuinely support their internal explorations of the question. Using criteria menus and other interactive interview enhancements at this early stage of the interview, however, requires careful monitoring of patron selfefficacy regarding computer literacy. A meta-analysis of various studies on this factor indicate significant negative consequences for young and middle-adulthood individuals who use computers, even 
though they have little expectation of being able to do so effectively. ${ }^{44}$

\section{Conducting the Search}

If the patron is involved in the search stage, issues of information overload and instructional need ${ }^{45}$ might complicate the process. In general, five stages of cognitive apprenticeships are recognized, and they serve as a framework for maintaining contact, appropriately engaging the user in the search, and guarding against information overload via instruction. Librarians can encourage (1) modeling (both behavioral and cognitive); (2) approximating, in which users try to work on their own; (3) scaffolding, in which librarians coach and otherwise guide the process; (4) fading, in which librarians step back, leaving the patron to work more independently; and (5) generalizing, in which patrons verbalize their plans for applying the lesson in another context. ${ }^{46}$ Neither sequential nor finite, these stages provide structure for the librarian while leaving ultimate control in the hands of the patron. In extremely brief encounters, "incidental learning" can address behavioral norms, communication patterns, mental model development, and other interview factors. ${ }^{47}$

Despite all efforts, some patrons reach and surpass their capacity for processing information (i.e., they reach information overload $^{48}$ ). If that happens, their method of handling the overload may shift responsibility for certain areas onto the librarian. This problem can be mitigated by editing, condensing, or segmenting the search process so that the patron can follow the work at a slower speed.

The relationship between agency (the "capacity to exercise control over the nature and quality of one's life" ${ }^{\prime 9}$ ) and selfefficacy provides one additional factor for this stage of the reference interview. Perceptions of self-efficacy influence the ways in which people adapt to situations and learn.

Such beliefs influence whether people think pessimistically or op- timistically and in ways that are selfenhancing or self-hindering. ... It is partly on the basis of efficacy beliefs that people choose what challenges to undertake, how much effort to expend in the endeavor, how long to persevere in the face of obstacles and failures, and whether failures are motivating or demoralizing. ${ }^{50}$

Obviously, the searching phase of the reference interview process could be strongly impacted by a patron's self-efficacy in terms of information technology skills, domain knowledge, and/or conceptual search strategies.

\section{Answering the Question}

Refined relevance criteria, new information needs, and cognitive dissonance may arise just as closure appears inevitable. Relevance criteria, like icebergs, consist of the visible and the hidden-from both the patron's and the librarian's perspectives. The initial query discussion may cover obvious matters objectively determined, such as publication date, language, audience (e.g., scholarly versus popular), availability (e.g., full text, library owned), and cost. In actually choosing among potential resources, however, the more subjective and internalized criteria come to the fore. The patron may need support in considering criteria such as the depth and scope of the information. Asynchronous communication is too clumsy to support this level of transactional communication, but synchronous contact can actually provide the reflective pauses that enhance it.

Recent research on the nature of "stopping rules" identified four patterns that may underlie relevance criteria applications. Even patrons who appear to have all their relevance criteria well met may not be ready to accept an "answer" to their question because their own stopping rule has yet to be invoked - that is, their search process does not yet feel complete to them. From a librarian's perspective, relevance criteria often tend to fit one 
common stopping rule (i.e., the "mental list" rule that lets people stop searching when each item on a predetermined list has been addressed). "Representational stability" can be quite difficult, however, because it requires a level of repetition across sources or channels before information is accepted as standard. A "difference threshold" takes that stopping rule one step further by looking for a lack of new information as a marker for stopping a search. Finally, the "magnitude threshold" simply looks until a preset number of items or preset range of qualities has been reviewed.$^{51}$ Librarians who answer a question in terms of the "mental list" stopping rule must be open to the possibility that patrons are using one or more of the other three rules instead.

Encountering novel information or facing the absence of expected information can trigger entirely new information needs on tangential or even separate issues. (It is even possible for information to be perceived when there is no actual awareness of that perception. ${ }^{52}$ ) Appropriately helping patrons anticipate and recognize unplanned information interactions when they happen strengthens mental models of the information-seeking process while enhancing self-efficacy.

The most complex issue, however, is that of cognitive dissonance. Although "there are instances in which we may welcome contradictory statements, in the long-term we drift toward information that supports our point of view. In other words, we tend toward a usual diet of information that is mostly congruent with our beliefs and opinions." ${ }^{53}$ Answers that push too hard against existing knowledge and belief structures may be discarded. Answers that demand too great an addition to an existing knowledge structure may be perceived as dissonant. Given the social components of the reference interaction, some patrons equate rejection of the information with rejection of the librarian's effort to provide it, making them unwilling to express dis- satisfaction with an answer. Ascertaining the actual level of cognitive cohesion requires the same level of focus as did the search itself. Developing an expectation of reiterative evaluation of resources might be, at least initially, necessary in digital interactions to encourage patrons to express their concerns about the usefulness of an answer.

\section{Making Sense of the Answer}

Patrons who have and approve of their answers must then try to make sense of them. If everything has gone smoothly in the earlier portions of an interview, the answer will fit the patron's internal reality and purpose, as well as reading level, format preference, and so on. However, some adjustment to the patron's cognitive constructs may be necessary and recent research in sociopsychology indicates just how difficult that adjustment can be. Information that violates a patron's perspective can generate a great a deal of anxiety as well as an effort to reconstruct or protect the original perspective. ${ }^{54}$ Use of evaluative integration builds on the need to continuously monitor, maintain, and update mental models by using effort and resources to examine model integrity when new information is encountered..$^{55}$ The process of creating meaning from information "is often more an ebb and flow as people begin to make sense of a situation. With each new insight, they may have to go back and question earlier understandings." 56

Librarians who are aware of this process can help support the process by continuing to provide or augment information as needed. Encouraging the patron to "go off-line" to check on the usefulness of the information by, for example, running a few searches or reading an article, can provide a warm and practical means of supporting the sense-making process. One advantage of the asynchronous interaction is the opportunity it provides for patrons to begin that sense-making process. 


\section{Closing the Interview}

Two problems commonly occur in ending an interview: lack of closure and premature closure. In digital communication, reliance on a preformatted response protocol can codify an offer of additional assistance so artificially as to almost indicate its opposite by abruptly moving from a personalized level of formality to a scripted closure. A pro forma offer of follow-up aid can signify such a lack of interest in the individual that only the most intrepid of patrons would actually be willing to say, "Please sir, may I have some more?"

Similarly, premature closure occurs when the librarian "gives up" on a problem or delivers a possible solution with no attempt to determine its usefulness. Particular care should be taken at closure, for example, when earlier interactions indicate that the patron has experienced computer-interaction problems. Such problems have been "found to be significantly related to individuals' general levels of susceptibility to cognitive failure $^{\prime \prime 57}$ and may, therefore, require more prolonged closure efforts.

\section{Conclusion}

Knowledge growth, a key purpose of most digital reference transactions, requires harmony among three types of knowledge: techne, episteme, and phronesis. Techne refers to "knowing how" whereas episteme refers to "knowing that."

Phronesis is the ethical knowledge that helps us grasp the relationship between the universal and the particular; it is what enables us to connect being and knowing.... Given the multifaceted nature of knowledge, we must remember that techne in the absence of episteme and phronesis may lead us to adopt practices that do not fully reach information seekers. ${ }^{58}$

The lure of digital reference lies often in the joy of techne and the satisfaction of episteme. Only phronesis, however, helps us effectively connect with the patron on a holistic level. As in every other aspect of digital reference service, librarians have a solid and interdisciplinary foundation on which to build. As we move into the second decade-the second stage- of online communication with our users, we must continue our practice of incorporating the latest research of psychology, education, communication, and human-computer interaction into our staff training.

\section{Notes}

1. David Tyckoson, "Reference at Its Core: The Reference Interview," Reference and User Services Quarterly 43, no. 1 (Fall 2003): 49-51.

2. For varied materials on the critical issues of management, see Bill Katz, editor, Digital Reference Services (New York: Haworth Pr., 2003); Joseph Janes, Introduction to Reference Work in the Digital Age (New York: Neal Schuman, 2003); Jana Smith Ronan, Chat Reference: A Guide to Live Virtual Reference Services (Westport, Conn.: Libraries Unlimited, 2003). For professional guidelines on virtual reference implementation, see MARS Digital Reference Guidelines Ad Hoc Committee, Guidelines for Implementing and Maintaining Virtual Reference Services, available online from http://www.ala.org/ala/rusa/rusaprotools/referenceguide/virtrefguidelines.htm. [Accessed 25 October 2004].

3. Carol Tenopir and Lisa Ennis, “A Decade of Digital Reference, 1991-2001," Reference and User Services Quarterly 41, no. 3 (Spring 2002): 264-73.

4. Deborrah Frable, "Gender, Racial, Ethnic, Sexual, and Class Identities," Annual Review of Psychology 48 (1997): 139-62.

5. Scaffolding, as the name implies, builds a small, skeletal, intellectual framework on the user's extant knowledge foundation and then slowly expands, as needed, to meet the information need by adding incrementally to the user's understanding.

6. See, for example, S. Kim Mcgregor and Yiping Lou, “Web-based Learnings: How Task Scaffolding and Web Site Design Support Knowledge Acquisition," Journal of Research on Technology 
in Education 37, no. 2 (Winter 2004-2005): 161-75. See also Michael Nussbaum et al., "Personality Interactions and Scaffolding in On-line Discussions," Journal of Educational Computing Research 30, nos. $1 \& 2$ (2004): 113-37.

7. Joseph Forgas, "Feeling and Thinking: Summary and Integration," in Feeling and Thinking: The Role of Affect in Social Cognition, ed. Joseph Forgas (Cambridge, U.K.: Cambridge Univ. Pr., 2000), 389.

8. Paula Niedenthal and Jamin Halberstadt, "Grounding Categories in Emotional Response," in Feeling and Thinking: The Role of Affect in Social Cognition, ed. Joseph Forgas (Cambridge, U.K.: Cambridge Univ. Pr., 2000), 359.

9. Forgas, "Feeling and Thinking."

10. Herbert Bless, "The Interplay of Affect and Cognition: The Mediating Role of General Knowledge Structures," in Feeling and Thinking: The Role of Affect in Social Cognition, ed. Joseph Forgas (Cambridge, U.K.: Cambridge Univ. Pr., 2000), 201.

11. Forgas, "Affect and Information-processing Strategies: An Interactive Relationship," in Feeling and Thinking: The Role of Affect in Social Cognition, ed. Joseph Forgas (Cambridge, U.K.: Cambridge Univ. Pr., 2000), 277.

12. Anthony Onwuegbuzie, Q. Jiao, and Sharon Bostick, Library Anxiety: Theory, Research, and Applications (Lanham, Md.: Scarecrow Pr., 2004).

13. Forgas, "Feeling and Thinking," 390.

14. Joseph Walther, Tracy Loh, and Laura Granka, "Let Me Count the Ways: The Interchange of Verbal and Nonverbal Cues in Computer-mediated and Face-to-face Affinity," Journal of Language and Social Psychology 24, no. 1 (Mar. 2005): 58.

15. Robin Nabi, "Exploring the Framing Effects of Emotion: Do Discrete Emotions Differentially Influence Information Accessibility, Information Seeking, and Policy Preference?" Communication Research 30, no. 2 (Apr. 2003): 243.

16. Robert Taylor, "Question-Negotiation and Information Seeking in Libraries," College and Research Libraries 29 (May 1968): 178-94.

17. Gary Olson and Judith Olson, "Human-Computer Interaction: Psychological Aspects of the Human Use of Computing," Annual Review of Psychology 54 (2003): 500.

18. Hartmut Mokros and Mark Aakhus, "From Information-seeking Behavior to Meaning Engagement Practice: Implications for Communication Theory and Research," Human Communication Research 28, no. 2 (Apr. 1, 2002): 303.

19. Donald Case, Looking for Information: A Survey of Research on Information Seeking, Needs, and Behaviors (Boston: Academic Pr., 2002), 84; Ronald Rice, Maureen McCreadie, and Shan-Ju Chang, Accessing and Browsing: Information and Communication (Cambridge, Mass.: MIT Pr., 2001), 176, $234+$.

20. Marie Radford, "Communication Theory Applied to the Reference Encounter," Library Quarterly 66, no. 2 (Apr. 1996): 132.

21. Forgas, "Affect and Information-processing Strategies," 256.

22. Joseph Janes, "Internet Librarian: Follow Their Lead, Dawg," American Libraries 35, no. 10 (Nov. 2004): 56.

23. John Bargh and Katelyn McKenna, "The Internet and Social Life," Annual Review of Psychology 55 (2004): 573.

24. John Suler, "The Online Disinhibition Effect," CyberPsychology E Behavior 7, no. 3 (2004): $321-26$

25. Bargh and McKenna, "The Internet and Social Life," 579.

26. Hiroshi Nittono, Shimizu Koichi, and Tadao Hori, "Subjectively Optimal Delay in Computer Response to a User's Voluntary Action," Perceptual E Motor Skills 99, no. 3 (Dec. 2004): 924.

27. J. Doyle and D. Ford, "Mental Models Concepts for System Dynamics Research," System Dynamics Review 14, no. 1 (1998): 17. For a discussion of mental models and reasoning, see P. N. Johnson-Laird, “Deductive Reasoning," Annual Review of Psychology 50: (1999): 109-35.

28. Arthur Markham and Dedre Gentner, "Thinking," Annual Review of Psychology 52 (2001): 231.

29. Alexandra Dimitroff, "Mental Models Theory and Search Outcome in a Bibliographic Retrieval System," Library and Information Science Research 14, no. 1 (1992): 54.

30. Ricard Downing, Joi Moore, and Steven Brown, "The Effects and Interaction of Spatial Visualization and Domain Expertise on Information Seeking," Computers in Human Behavior 21 (2005): 195-209.

31. Vincent Aleven et al., "Help Seeking and Help Design in Interactive Learning Environments," Review of Educational Research 73, no. 3 (Fall 2003): 284

32. Scott Brandt, "Reference, Mental Models and Teaching Technology," Reference Librarian 74 (2001): 44-45. 
33. Jacquelynne Eccles and Allan Wigfield, "Motivational Beliefs, Values, and Goals," Annual Review of Psychology 53 (2002): 124.

34. Lori Thompson and Brian Lynch, "Web-based Instruction: Who Is Inclined to Resist It and Why?" Journal of Educational Computing Research 29, no. 3 (2003): 375-85.

35. Allen Foster, "A Nonlinear Model of Information-seeking Behavior," Journal of the American Society for Information Science and Technology 55, no. 3 (2004): 228-37.

36. Amos Lakos, "Portals in Libraries: Portal Vision," Bulletin of the American Society for Information Science and Technology 31, no. 1 (Oct./Nov. 2001): 9. For an overview of the cognitive psychology and educational theory possibilities inherent in research on the use of such portals in digital libraries, see David Rapp, Holly Taylor, and Gregory Crane, "The Impact of Digital Libraries on Cognitive Processes: Psychological Issues of Hypermedia," Computers in Human Behavior 19 (2003): 609-28.

37. Irina Ceaparu et al., "Determining Causes and Severity of End-user Frustration," International Journal of Human-Computer Interaction 17, no. 3 (Sept. 2004): 333+.

38. Linda Jackson, Kelly Ervin, Phillip Gardner, and Neal Schmitt, "Gender and the Internet: Women Communicating and Men Searching," Sex Roles 44, no. 5/6 (Mar. 2001): 363.

39. Kathleen Kern, "Communication, Patron Satisfaction, and the Reference Interview," Reference and User Services Quarterly 43, no. 1 (Fall 2003): 47-49.

40. Anita Komlodi, “Task Management Support in Information Seeking: A Case for Search Histories," Computers in Human Behavior 20 (2004): 163-84.

41. Antti Oulasvirta and Pertti Saariluoma, "Long-term Working Memory and Interrupting Messages in Human-Computer Interaction," Behaviour \& Information Technology 23, no. 1 (Jan.-Feb. 2004): 53-64.

42. Smith Ronan, Chat Reference, 146-49; see also Jody Condit Fagan and Christina Desai, "Communication Strategies for Instant Messaging and Chat Reference Service," in Digital Reference Services, ed. Bill Katz (Binghamton, N.Y.: Haworth Pr., 2003), 121-55.

43. Donald Cunningham, "Fear and Loathing in the Information Age," Cybernetics \& Human Knowing 8, no. 4 (2001): 64-74.

44. Timothy Poynton, "Computer Literacy across the Lifespan: A Review with Implications for Educators," Computers in Human Behavior 21 (2005): 861-72.

45. For an overview of schema, cognitive load, and retention theories in the HCI context, see Patricia Chalmers, "The Role of Cognitive Theory in Human-Computer Interface," Computers in Human Behavior 19 (2003): 593-607.

46. Catherine Hansman, "Context-based Adult Learning," in The New Update on Adult Learning Theory, ed. Sharan Merriam (San Francisco: Jossey-Bass, 2001), 47.

47. Tracy Bicknell-Holmes and Paul Seth Hoffman, "Elicit, Engage, Experience, Explore: Discovery Learning in Library Instruction," Reference Services Review 28, no. 4 (2000): 313-22.

48, For an HCI approach to mitigating information overload that incorporates several of these tactics into system design, see Kay Stanney et al., "A Paradigm Shift in Interactive Computing: Deriving Multimodal Design Principles from Behavioral and Neurological Foundations," International Journal of Human-Computer Interaction 17, no. 2 (2004): 229-57.

49. Albert Bandura, "Social Cognitive Theory: An Agentic Perspective," Annual Review of Psychology 52 (2001): 1.

50. Ibid., 10.

51. Glenn Browne and Mitzi Pitts, "Stopping Rule Use during Information Search in Design Problems," Organizational Behavior and Human Decision Processes 95 (2004): 219.

52. Philip Merikle, Daniel Smilek, and John Eastwood, "Perception without Awareness: Perspectives from Cognitive Psychology," Cognition 79 (2001): 131.

53. Donald Case, Looking for Information: A Survey of Research on Information Seeking, Needs, and Behaviors (Boston: Academic Pr., 2002), 93 [emphasis in original].

54. Jason Plaks, Heidi Grant, and Carol Dweck, "Violations of Implicit Theories and the Sense of Prediction and Control: Implications for Motivated Person Perception," Journal of Personality and Social Psychology 88, no. 2 (Feb. 2005): 245-62.

55. Forgas, "Feeling and Thinking," 398.

56. Victoria Marsick and Karen Watkins, "Informal and Incidental Learning," in The New Update on Adult Learning Theory, ed. Sharan Merriam (San Francisco: Jossey-Bass, 2001), 29.

57. Gregory Jones and Maryanne Martin, "Individual Differences in Failing to Save Everyday Computing Work," Applied Cognitive Psychology 17 (2003): 861-68.

58. John Budd, "Information Seeking in Theory and Practice: Rethinking Public Services in Libraries," Reference and User Services Quarterly 40, no. 3 (Spring 2001): 256-63. 